\title{
Review
}

\section{Improving the Techniques for Human Hepatocyte Transplantation: Report From a Consensus Meeting in London}

Juliana Puppi,* Stephen C. Strom, $\dagger$ Robin D. Hughes,* Sanjay Bansal, $\ddagger$ Jose V. Castell, $\S \mathbb{I}$ Ibrahim Dagher,\#** Ewa C. S. Ellis, $\uparrow \dagger$ Greg Nowak, $\dagger \dagger$ Bo-Goran Ericzon, $\dagger \dagger$ Ira J. Fox,

M. José Gómez-Lechón,đI Chandan Guha,§§ Sanjeev Gupta,đII Ragai R. Mitry,*

Kazuo Ohashi,\#\# Michael Ott,*** Lola M. Reid,††† Jayanta Roy-Chowdhury, $+\neq \neq$ Etienne Sokal, $\S \S$ Anne Weber,** and Anil Dhawan*末

*Institute of Liver Studies, King's College London School of Medicine at King's College Hospital, London, UK $†$ Department of Pathology, University of Pittsburgh, Pittsburgh, PA, USA

$\$$ Paediatric Liver, GI \& Nutrition Centre, King’s College Hospital, London, UK

§Departamento de Bioquímica y Biología Molecular, Facultad de Medicina, Universidad de Valencia, Valencia, Spain IUnidad de Hepatología Experimental, Centro de Investigación, Hospital La Fe, Valencia, Spain

\#Department of Surgery, Antoine Béclère Hospital, Assistance Publique-Hôpitaux de Paris (AP-HP), Clamart, France

**Institut National de la Santé et de la Recherche Mèdicale (INSERM) Unité 972, Institut Fédératif de Recherche 93 , Bicêtre Hospital, Kremlin-Bicêtre, France

$\dagger$ Division of Transplantation Surgery, Department of Clinical Science, Intervention and Technology (CLINTEC), Liver Cell Laboratory, Karolinska University Hospital Huddinge, Stockholm, Sweden

$\$ \neq$ Department of Surgery, and McGowan Institute for Regenerative Medicine, University of Pittsburgh School of Medicine, Pittsburgh, PA, USA

$\S \S$ Department of Radiation Oncology, Montefiore Medical Center, Albert Einstein College of Medicine, New York, NY, USA

IIIDEepartments of Medicine and Pathology, Marion Bessin Liver Research Center, Diabetes Research Center, and Cancer Research Center, Albert Einstein College of Medicine, New York, NY, USA

\#\#Institute of Advanced Biomedical Engineering and Science, Tokyo Women's Medical University, Tokyo, Japan

***Department of Gastroenterology, Hepatology and Endocrinology, Hannover Medical School and Twincore Centre for Experimental and Clinical Infection Research, Hannover, Germany

$+\dagger+$ Department of Cell and Molecular Physiology and Department of Biomedical Engineering Program in Molecular Biology and Biotechnology, School of Medicine University of North Carolina, Chapel Hill, NC, USA

$\$+\neq$ Departments of Medicine and Genetics, Marion Bessin Liver Research Center, Albert Einstein College of Medicine, New York, NY, USA

$\S \S \S$ Catholic University of Louvain and St Luc Clinics, Paediatric Department (HPED), PEDI Unit, Laboratory of Paediatric Hepatology and Cell Therapy, Brussels, Belgium

\begin{abstract}
On September 6 and 7, 2009 a meeting was held in London to identify and discuss what are perceived to be current roadblocks to effective hepatocyte transplantation as it is currently practiced in the clinics and, where possible, to offer suggestions to overcome the blocks and improve the outcomes for this cellular therapy. Present were representatives of most of the active clinical hepatocyte transplant programs along with other scientists who have contributed substantial basic research to this field. Over the 2-day sessions based on the experience of the participants, numerous roadblocks or challenges were identified, including the source of cells for the transplants and problems with tracking cells following transplantation. Much of the discussion was focused on methods to improve engraftment and proliferation of donor cells posttransplantation. The group concluded that, for now, parenchymal hepatocytes isolated from donor livers remain the best cell source for transplantation. It was reported that investigations with other cell sources, including
\end{abstract}

Received November 21, 2010; final acceptance February 18, 2011. Online prepub date: April 1, 2011.

Address correspondence to Professor Anil Dhawan, M.D., FRCPCH, Paediatric Liver Centre, King's College Hospital, King's College London School of Medicine, Denmark Hill, London SE 5 9RS, UK. Tel: +44 (0)20 3299 3578; Fax: +44 (0)20 3299 4228; E-mail: anil.dhawan@kcl.ac.uk 
stem cells, were at the preclinical and early clinical stages. Numerous methods to modulate the immune reaction and vascular changes that accompany hepatocyte transplantation were proposed. It was agreed that, to obtain sufficient levels of repopulation of liver with donor cells in patients with metabolic liver disease, some form of liver preconditioning would likely be required to enhance the engraftment and/or proliferation of donor cells. It was reported that clinical protocols for preconditioning by hepatic irradiation, portal vein embolization, and surgical resection had been developed and that clinical studies using these protocols would be initiated in the near future. Participants concluded that sharing information between the groups, including standard information concerning the quality and function of the transplanted cells prior to transplantation, clinical information on outcomes, and standard preconditioning protocols, would help move the field forward and was encouraged.

Key words: Hepatocyte transplantation; Engraftment; Radiation; Stem cell; Metabolic liver disease

\section{INTRODUCTION}

Liver transplantation is currently the treatment of choice for patients with end-stage liver disease and acute liver failure (ALF). However, the number of patients waiting for a liver transplant greatly outnumbers available donors. Even with improvements in donor schemes, the use of broader donor criteria, and recent advances in surgical techniques, such as split-liver and living-related liver donor grafts, there has only been a small increase the number of transplants (61).

Hepatocyte transplantation (HT) has been performed as an alternative to orthotopic liver transplantation (OLT) to treat some liver-based inborn errors of metabolism and liver failure $(18,49,55)$. Clinical observations have demonstrated the safety of the procedure and patients who have undergone HT showed clinical improvement and/or partial correction of the underlying metabolic defect. However, in the majority of the cases, sustained benefits were not observed.

In an effort to identify and discuss possible strategies to overcome the limitations of the technique, experts in the field of human hepatocyte transplantation met in London on September 6 and 7, 2009. The meeting focused on alternative sources of hepatocytes needed to overcome the shortage of organ donors and the lack of standardization of the quality of cells used, which make it difficult to compare the results of human hepatocyte transplantation reported in the literature. Clinical application of techniques to precondition the liver with the aim of improving hepatocyte engraftment and repopulation after transplantation was identified as a key issue. Overall, the purpose of this meeting was to consider new techniques that could be applied to improve the outcome of clinical HT. This review summarizes the content of the meeting and as a result reflects the topics discussed and comments made by the attendees. It is thus not a comprehensive review of the literature or an exhaustive review of each topic.

\section{HUMAN HEPATOCYTE TRANSPLANTATION}

The major challenge that this field is facing is the limited supply of donor organs that are available to isolate good quality cells. Hepatocyte transplantation must compete for organs with liver transplantation, the wellestablished treatment for liver disease. Hence, the current source of hepatocytes is mainly donor organs deemed unsuitable for whole organ transplantation, which are often of marginal quality. Organs from brain-dead donors, organs from donation after cardiac death (DCD) with less than $40 \mathrm{~min}$ of warm ischemia, or organs from extended age donors are typical sources for cell isolation. If the efficacy of hepatocyte transplantation were firmly established, other sources of tissue such as a split of a liver being used for OLT or even a live donor segment could be considered when the benefit of the cellular transplant were judged to be equal to or greater than risk of the added surgical procedure.

\section{Cell Quality and Clinical Outcome}

The outcome of HT is closely related to the quality of the hepatocytes transplanted. If fresh cells are transplanted, rapid and sensitive assays to evaluate their viability and function are needed in order to determine their suitability for transplantation.

In the majority of the published reports of hepatocyte transplantation trypan blue exclusion was the sole test for cell viability. Trypan blue exclusion reflects cell viability at that point in time based on cell membrane integrity, but its correlation with cell metabolic function and the potential of cells to engraft has yet to be determined. Given its simplicity, the trypan blue exclusion test should be performed on cells at the end of isolation, after thawing cryopreserved cells, and pre- and postinfusion. ATP production is also a quality assay that may prove efficient to estimate cell viability and functional activity; however, until proven otherwise, we assume that engraftment in the liver will correlate with the plating efficiency of cells - that is, the ability of cells to attach and survive long term (3-7 days) on culture plates precoated with a suitable substrate.

Other assays to determine the quality of the cells that could be performed within $2 \mathrm{~h}$ of cell isolation were discussed in the meeting. Donato et al. (13) recently demonstrated that it is possible to determine up to 10 parameters to estimate the quality of hepatocyte preparations 
in $1 \mathrm{~h}$. In addition to the trypan blue exclusion test and plating efficiency, assays were used to determine the cell metabolic competence, urea synthesis and drug-metabolizing P450 activities (CYP1A2, 2A6, 2C9, 2C19, 2D6, $2 \mathrm{E} 1$, and $3 \mathrm{~A} 4$ ) performed by mass spectrometry in hepatocyte suspensions. Determination of the metabolic signature of the cells using techniques such as ${ }^{1} \mathrm{H}$ nuclear magnetic resonance (NMR) spectroscopy, and noninvasive quantification of cellular mitochondrial respiration can also be performed rapidly and can provide valuable information on the quality of cells. However, they need sophisticated equipment that may not be available in each cell isolation laboratory. They are more relevant when hepatocytes are cryopreserved and there is more time to perform the assays.

However, studies where the endpoint of the metabolic process results in a fluorescent, luminescent, or visible colored metabolite can provide rapid and sensitive methods to assess a wide variety of hepatic functions within $2 \mathrm{~h}$ of cell isolation with fewer than 40,000 cells with simple equipment readily available in most laboratories (luminometers and fluorescent spectrophotometers) (21). It is not currently known which tests will be useful to predict long-term engraftment and function following transplantation, but the collection of data on a standard battery of assays designed to measure multiple hepatic functions combined with retrospective analysis of cellular function, in vivo, should prove useful and is encouraged.

Engraftment efficiency in suitable recipient animals is considered the best surrogate marker of cells useful for transplant. Because of the time frame for the study, this test can only be interpreted in retrospect. Even an assessment of the engraftment in animals has limitations, as the efficacy of human hepatocyte engraftment and repopulation of a rodent liver may be suboptimal due to incompatibilities of growth factor and cytokine response and cell-to-cell and cell-to-matrix interactions.

Some centers in Europe only transplant cryopreserved hepatocytes that have been characterized for a number of functions prior to clinical transplantation. Cryopreservation allows cell banking and flexibility in the timing of cell delivery to patients. Discrepancies in the clinical results between different centers and even different patients in the same center may, in part, be related to differences in cell quality after isolation and cryopreservation, so the use of banked hepatocytes offers the advantage or more time for extensive microbiological testing and quality control studies prior to transplantation. However, freshly isolated cells generally have better viability and plating efficiency than cryopreserved cells, and are likely to engraft better than previously cyropreserved cells. Studies have shown that cryopreservation is associated with mitochondrial damages, loss of capacity for ATP synthesis and abnormal respiratory chain enzyme activity, increased mitochondrial permeability, and impaired respiration $(56,59)$.

Targeted analysis of specific liver functions may be particularly useful for transplants of patients with metabolic disorders because cells could be screened for useful levels of the expression of the metabolic activity missing in the recipient prior to transplantation. To date, liver-based inborn errors of metabolism have been the main indication for hepatocyte transplantation, in particular urea cycle defects and Crigler-Najjar syndrome type 1. Recently, Bonora-Centelles et al. (7) proposed specific assessment of cells prior to infusion for urea synthesis from ammonia and UDP-glucuronosyltransferase $1 \mathrm{~A} 1$ activity, with an assay using $\beta$-estradiol as substrate, allowing the possibility of customizing cell preparation for patients affected with disorders in these pathways. As indicated above, because of time constraints with freshly isolated cells, assays of specific function prior to transplantation have only been conducted on previously cryopreserved cells.

\section{STANDARD INFORMATION TO BE REPORTED FROM CELLULAR TRANSPLANTS}

The participants of the meeting concurred that in order to make progress in the field it would be helpful to be able to directly compare clinical outcomes after hepatocyte transplantation when performed by different groups. Therefore, it would be necessary to report all the collected data on the quality of the cells to facilitate comparison of patients' outcomes (retrospective data). Details of the donor selection criteria, such as age, sex, previous drug treatments, warm and/or cold ischemia time, presence of steatosis, and reason for rejecting liver tissue for organ transplantation, are some of the data that would be relevant when analyzing the outcomes after hepatocyte transplantation. If cells from multiple donors have been transplanted, individualized reports of the data would give more valuable information. In the case of split-livers, information about the outcome in the liver tissue recipient(s) should be obtained, as it could indirectly assess the quality of cells used for hepatocyte transplantation. Systematic biopsy of the liver before processing could be helpful not only for histological analysis, but also for molecular analysis of parameters such as oxidative stress and apoptosis. At present, it is not known which parameters of cell quality correlate best with engraftment or a favorable clinical outcome. It was concluded that if standard information concerning the quality assessment of the cells prior to transplantation and the clinical outcome was compiled in a database, such an analysis would become feasible.

\section{WHAT ARE THE ALTERNATIVES?}

To move the field forward, a reliable source of cells is needed, but at present it is not clear which cell 
source(s) is/are the most promising. The characteristics of the cell source might vary from cells expressing the specific missing protein or enzyme to cells presenting full hepatocyte function (hepatocyte-like cells) according to the indication for liver cell transplantation. Cells being considered for potential clinical application include fetal human hepatocytes, mesenchymal stem cells (MSCs) from a variety of sources including liver, amnion epithelial cells, and xenotransplants with porcine hepatocytes. It was appreciated that for some cell sources, it would take some time before clinical application was feasible.

\section{Fetal Liver Progenitor Cells}

Hepatoblasts, the hepatic progenitor cell population present in fetal and neonatal livers, rapidly decline in number with age, and are almost undetectable in adult livers (52). Numerous animal experiments have been performed to evaluate the capacity of human fetal liver cells to engraft and repopulate the recipient liver. Transplantation of cryopreserved hepatoblasts from early fetal livers (11-13 weeks of gestation) into the liver of newborn athymic mice resulted in up to $10 \%$ of liver repopulation and cells expressed markers of differentiated adult hepatocytes (39). These results could not be reproduced in an immunodeficient heterozygous albuminurokinase-type plasminogen activator (uPA) mouse, where transplanted human fetal liver cells (14-17 weeks of gestation) resulted in a lower degree of liver repopulation than adult human hepatocytes (25). However, differences in age (newborn or adult) in host or donor cells and/or species differences may also affect repopulation and maturation. Recently it was demonstrated by ${ }^{111}$ indium labeling of cells that the biodistribution of fetal liver cells and adult hepatocytes were similar and restricted to the liver, without translocation into pulmonary or systemic circulations (10). Quantification of mature gene expression levels in donor cells was not investigated in any of these studies, so the level of maturation of the fetal cells posttransplant remains unknown. Since mature liver genes are frequently expressed at $1-5 \%$ of normal levels found in adults, it is important to determine the rate at which fetal hepatoblasts mature following transplant before their suitability for liver support can be assessed.

There are a number of potential advantages in using fetal cells. Cell viability is normally high after cell isolation, they maintain some stem cell properties, can be expanded in culture, and, in rodents, without species incompatibilities, these cells have shown significant liver repopulation capacity. However, at present the clinical application of this cell source is restricted due to the difficulty in obtaining large numbers of fetal liver cells. To transplant a quantity of cells corresponding to an estimated $2 \%$ of the liver mass of a newborn, for example, around 30 fetal livers (12 weeks gestation) would be needed. A recent report of a child with ataxia telangiectasia treated with intracerebellar and intrathecal injection of human fetal neural stem cells, who developed a multifocal brain tumor 4 years after the experimental treatment, raises concerns over the safety of this experimental therapeutic approach. Molecular and cytogenetic studies showed that the tumor was of non-host origin, suggesting it was derived from the transplanted neural stem cells (2). This underlines the importance of the process of informed consent as a central component of any experimental study giving enough information to patients to make sure they understand and accept the potential risks.

\section{Mesenchymal Cells and Hepatocyte Progenitors Derived From Liver}

Bone marrow-derived MSCs are already widely used in medicine and currently there are over $60 \mathrm{MSC}$ ongoing clinical trials with no safety risk demonstrated in humans so far (45). MSCs, which are usually autologous, can be isolated, expanded, and utilized for a variety of therapeutic applications, including the treatment of inflammatory, cardiovascular, and orthopedic diseases.

Mesenchymal-like cells have also been isolated from adult liver tissue. This cell population can proliferate to a certain extent and differentiate into hepatocyte-like cells with more specific hepatocytic phenotype compared to bone marrow- or Wharton's jelly-derived cells (8). Studies conducted in vitro have shown a range of hepatic functions including drug metabolizing enzymes (30). Preliminary studies in immunodeficient uPA mice confirmed their ability to engraft and differentiate into hepatocyte-like cells in vivo (44). Recent reports suggest that they also play a role of trophic support in injured livers by inhibiting endogenous hepatocyte death and stimulating their proliferation $(62,64)$. In culture, they enter a phase of replicative senescence after a limited number of population doubling (5).

Small cells, termed liver-derived progenitor cells (LDPC), have been cultured, in vitro, from cells derived by collagenase perfusion of rodent liver. These cells proliferate extensively in culture and can give rise to hepatocytes after engraftment into the liver (9).

The use of manipulated cells is considered a medicinal product, and most preclinical studies are focused on safety. Although there have been no safety problems so far, studies to investigate tumorigenicity, the purity of the preparations, and cytogenetic studies to assess clonal chromosomal rearrangements are still needed before their clinical application. Preclinical safety studies in nonhuman primates remain highly debated, as these have not been shown to be more relevant than the standard toxicology studies in rodents. 


\section{Xenotransplantation}

Xenotransplantation is one possible alternative to overcome the shortage of donor organs, and pigs represent a possible source of liver to obtain liver cells. Pig hepatocytes represent a readily available source of cells for scheduled or emergency transplantation, allowing repeated cell infusions if required. The quality of hepatocytes isolated from donor pigs is consistent and, in contrast to donor human hepatocytes, are not compromised by comorbidities, warm and/or cold ischemia injury, and senescence. Furthermore, the risks of infectious disease transmission associated with xenografting of hepatocytes are minimal, if cells are isolated from designated pathogen-free donor pigs.

Preformed antibodies against a particular porcine carbohydrate moiety $(\mathrm{Gal})$ are responsible for triggering hyperacute rejection of pig organs transplanted into primates (20). Gal gene knockout pigs (48) have been developed, and the use of their organs for transplantation into nonhuman primates has resulted in prolonged survival (36). Lessons learned from islet xenotranplantation suggest that, unlike vascularized solid organ xenografts, the rejection of porcine islet xenografts in nonhuman primates is associated with a predominant T-cell infiltrate (19). The demonstration by several groups of pig islet xenograft survival for months and the recent achievement of prolonged insulin independence in diabetic monkeys indicates that these cellular xenografts do not undergo hyperacute rejection as observed in vascularized organ transplants (26). Furthermore, no increase in anti-Gal antibody levels were observed, and wild-type pig islets were not more susceptible to early posttransplant graft loss than islets from Gal-knockout pigs $(27,51)$.

Encouraging results were also achieved with transplantation of porcine hepatocytes into the spleen of cynomolgus monkeys, which were shown to secrete albumin for over 80 days after transplantation under conventional immunosuppression (43). In addition, intrasplenic transplantation of porcine hepatocytes into rats with decompensated liver failure resulted in restoration of liver function and prolonged survival for a period of weeks without immunosuppression (42). Regarding clinical translation, the immune system of patients with liver failure is so compromised at the time of transplantation that, at least initially, the need for immunosuppression would probably be low. The consensus of the meeting was to produce more preclinical data in the pigto-primate model as a necessary step to further consideration of pig-to-human HT.

Although not discussed at the meeting, another approach using xenotransplantation is to microencapsulate hepatocytes as a barrier to immune attack. Porcine hepatocytes encapsulated in alginate administered intraperitoneally significantly improved survival in a mouse model of fulminant hepatic failure (41) and could be worthy of further development.

\section{HOW TO IMPROVE LIVER ENGRAFTMENT AND REPOPULATION?}

The outcome of hepatocyte transplantation has also been limited by the low efficiency of integration of transplanted cells into the host liver parenchyma. In animal models, after intraportal transplantation, adult hepatocytes are restricted to the liver, without translocation to pulmonary or systemic circulations (10). Similar results were observed when the biodistribution of human hepatocytes was analyzed in a clinical setting (6). Most of the transplanted hepatocytes $(>70 \%)$ remain wedged in the portal spaces and sinusoids, and are recognized as "non-self" by the immune system, including Kupffer cells and neutrophils, and are cleared within 24-48 h $(23,29)$. The presence of cells in the vascular beds is inevitably associated with inflammation, tissue injury, and ischemic events, stimulating the release of vascular endothelial growth factor (VEGF) by donor cells and surrounding hepatocytes and endothelial cells as well as cytokines by Kupffer cells, which induce vascular permeability and sinusoidal endothelium disruption, allowing surviving hepatocytes to reach the space of Disse. Integration of transplanted hepatocytes into the host liver parenchyma requires reconstitution of plasma membrane structures, which takes around 3-7 days to occur in animal models $(23,33)$. Once engrafted in the liver plates, the transplanted cells can survive indefinitely in syngeneic models. In humans, however, where allogeneic cells are normally transplanted, after successful engraftment hepatocytes may also face a cell-mediated immune response, evoked by both $\mathrm{CD}^{+}$and $\mathrm{CD} 8^{+}$ $\mathrm{T}$ cells, which may contribute to the gradual loss of graft function that is frequently observed $(1,24)$.

\section{Alternative Site for Transplantation}

To date, the liver has been the primary site for hepatocyte transplantation by infusing the cells through the portal circulation. Transplantation of cells into extrahepatic sites such as the peritoneal infusion of cells has been reported in few clinical cases. Other sites (e.g., subrenal, subcutaneous, or intramuscular spaces) are being explored $(46,47,58,60)$. The therapeutic potential of ectopic hepatocyte transplantation has been demonstrated in animal models, including hemophilia and ascorbic acid deficiency $(46,60)$. Much additional work will be needed before it can be determined if ectopic transplantation procedures will be practical and viable in the clinic. 


\section{Prevention of Early Loss of Transplanted Cells}

Controlling Liver Inflammation. Various approaches have been used to improve cell engraftment in preclinical models. In rodents depletion of neutrophils or Kupffer cells have improved engraftment of transplanted cells (29, $35)$. Recently it was also demonstrated that within $6 \mathrm{~h}$ of syngeneic HT there is upregulation of numerous cytokine-chemokine genes associated with activated neutrophils and macrophages, including chemokine ligands and receptors and regulatory cytokines such as tumor necrosis factor- $\alpha$ and interleukin-6 (35). This suggests targets that could be directly modulated with drugs to improve cell engraftment. It has also been shown in rodents that during the early clearance of transplanted cells from the liver the hepatic cyclooxygenase pathways (COX-1 and COX-2) involved in the synthesis of prostaglandins, prostacyclins, thromboxanes, and other prostanoids are activated. Drugs that specifically block prostaglandin-endoperoxide synthases stimulated stellate cells to release hepatocyte protective factors, such as hepatocyte growth factor (HGF) and VEGF, and matrix-type metalloproteinases, which regulate hepatic remodeling and improved cell engraftment (15).

Inhibiting Activation of Coagulation. Isolated hepatocytes were shown to express both soluble and membrane-bound forms of tissue factor, which have procoagulant activity, contributing to early loss of transplanted cells. In vitro experiments demonstrated that $\mathrm{N}$ acetyl-L-cysteine inhibits this tissue factor-dependent activation of coagulation (57).

Controlling Vascular Changes in the Liver. Splanchnic vasodilators, such as nitroglycerine, have been shown in rodent models to increase transplanted cell entry into liver sinusoids, which led to improved cell engraftment and decreased microcirculatory perturbations, without significantly increasing intrapulmonary cell translocation (54).

Reversible Sinusoidal Endothelium Disruption. There is endothelial damage when cells are injected into the liver circulation, which is part of the engraftment process and takes around $48 \mathrm{~h}$ to resolve. Rats treated with agents that disrupt hepatic sinusoidal endothelial cells, such as cyclophosphamide and doxorubicin, accelerated the entry and increased engraftment of transplanted hepatocytes into the liver parenchyma $(31,40)$.

\section{Liver Preconditioning and Proliferation Stimulus}

The different strategies used in preclinical models mentioned above have been shown to improve cell engraftment after hepatocyte transplantation; however, they do not induce subsequent cell proliferation and liver repopulation. Although it is believed that engrafted hepatocytes have the capacity to proliferate, they do not express this property unless they are induced to proliferate in response to a mitotic stimulus (16). A selective growth advantage of transplanted hepatocytes with near total liver repopulation has been demonstrated in various animal models where the liver was preconditioned using drugs that impaired native liver regeneration, followed by a proliferation stimulus $(28,37)$. Recent reports indicate that human hepatocytes also have an extensive capacity to proliferate and repopulate the liver of immunodeficient Fah or urokinase-type plasminogen activator transgenic mice $(4,58)$. In these studies, transplantation of primary human cells into the liver resulted in repopulation of the mouse liver with human hepatocytes that maintained human hepatocyte-specific functions including albumin and coagulation factor production and CYP450 gene expression and metabolic function. Subsequent isolation of human hepatocytes from the "humanized" mouse liver followed by serial transplantation through four generations of mice was demonstrated, which required an estimated greater than $10^{10}$-fold expansion of the population of cells originally transplanted. Thus, in this animal model, human hepatocytes even from individuals $>60$ years of age still display remarkable proliferation potential. Thus, in the clinical transplants, the lack of robust proliferation in the recipient liver following transplantation is most likely due to lack of regenerative stimulus on the part of the host. Methods to increase proliferation of transplanted cells should have a high probability of success.

Hepatic Irradiation. In animal models, hepatic irradiation at low dose has been shown to improve cell engraftment and proliferation. Enhanced engraftment is likely mediated by short-term disruption of hepatic sinusoidal endothelial cells, observed after $24 \mathrm{~h}$ by electron microscopy, and by suppression of the phagocytic activity of Kupffer cells. Hyaluronic acid, which is cleared from the circulation by sinusoidal endothelial cells by receptor-mediated endocytosis, was found to start increasing as early as $6 \mathrm{~h}$ after hepatic irradiation and returned to preirradiation levels in 7 days (63). Therefore, optimal timing for HT after hepatic irradiation ranges from 1 to 7 days. In addition, hepatic irradiation doses ranging from 15 to $50 \mathrm{~Gy}$ in rodents resulted in a temporary block of the native cell cycle (arrest in the $G_{1} / S$ phase), which promoted preferential proliferation of transplanted hepatocytes in response to a mitotic stimulus, resulting in extensive repopulation of the host liver $(32,34,63)$. However, there is the concern that hepatic irradiation activates stellate cells, which in the long term could produce irradiation-induced liver fibrosis (53).

It is important to take into consideration that there are species differences in response to hepatic irradiation, 
and rodents are generally more resistant. In cynomolgus monkeys, a single $10 \mathrm{~Gy}$ dose of hepatic irradiation was sufficient to enhance the engraftment of porcine hepatocytes after transplantation (63). However, with whole liver irradiation (>40 Gy) the animals developed irradiation-induced liver disease and died within 6 weeks.

The human liver is very radiosensitive. A single 30 Gy dose of whole liver irradiation can cause liver failure due to endothelial damage and consequent veno-occlusive disease. On the other hand, a third of the liver can be irradiated with doses as high as 90-100 Gy with no adverse consequences to the whole organ, indicating that the volume of liver irradiated is important in the process. As hepatic irradiation has not yet been used as a liver preconditioning method for clinical hepatocyte transplantation, definition of patients and diseases that could possibly benefit from this technique is important and was discussed in the meeting. Available data on liver irradiation for infants $<2$ years of age is inconclusive, but they are at greater risk of developing complications, such as central nervous system neoplasms and rib cage deformities. For children $>2$ years, single fractions of 3-5 Gy are definitely safe if performed in focal parts of the liver, but whether this would promote sufficient repopulation with donor cells is unknown.

The safety of the patient is the main concern for the procedure. Accordingly, it is now considered that hepatic irradiation should be delivered in a single fraction and confined to a portion of one lobe of liver. Careful selection of patients is equally important. Cirrhotic patients should be avoided as their livers are more sensitive to radiation. The first choice of patients will be those presenting with diseases in which the therapeutic effects of transplanted cells can be readily measured and who are also candidates for organ transplantation, should rescue therapy be required if the procedure is not successful. Donor hepatocytes should be transplanted within 7 days of hepatic irradiation, although ideally after $24 \mathrm{~h}$. If the planned initial studies with these techniques establish that liver preconditioning with hepatic irradiation is safe and results in an improvement in engraftment, this will certainly open new opportunities in the field of hepatocyte transplantation.

Portal Vein Embolization. Permanent portal vein embolization (PVE) is a safe procedure that is widely used in the surgical setting to induce hypertrophy of the contralateral lobe and prevent postresection liver failure due to insufficient liver remnant. In a nonhuman primate model, Dagher et al. (11) demonstrated that definite occlusion of the left and right anterior portal branches (corresponding to $50 \%$ of the liver after left lateral resection) significantly improved engraftment of hepatocytes after autologous cell transplantation and resulted in repopulation of $10 \%$ of the nonembolized lobe. There was no regeneration in the embolized lobe. The left lateral segment used for hepatocyte isolation corresponded to $20 \%$ of the liver mass. However, regeneration studies did not show significant difference when compared with liver embolization without resection.

The use of reversible PVE represents a less invasive approach to induce liver regeneration. Lainas et al. (38) showed that PVE performed in the same nonhuman primate preclinical model using an absorbable material (gelfoam) powder that allows very distal infusion resulted in a more complete portal obstruction. The procedure induced significant hepatocyte proliferation and hypertrophy of the nonembolized lobes. Complete portal vein recanalization after reversible embolization occurred on average within 13 days. The material used for embolization causes some inflammatory reaction, which is reversible. Longer term follow-up showed that up to $6 \%$ of recipient liver resulted from donor hepatocytes 3 months after transplantation. Comorbidities, such as liver cirrhosis and diabetes, could decrease the extent of liver regeneration.

Clinical translation of the technique is underway and it will be performed as a single procedure, with reversible percutaneous embolization performed first, followed by hepatocyte infusion. A slight and transitory increase in the portal pressure normally occurs after embolization, and should have returned to normal levels before cell transplantation is performed.

Partial Hepatic Resection. Improved techniques and increased activities at experienced centers have made liver resection and living donor liver transplantation a common procedure. Hepatectomy as a pretreatment for hepatocyte transplantation to induce regeneration and proliferation should be considered. The surgical procedure would likely be much safer than when partial hepatic resections are performed for tumor removal or for living donor harvest. The location of the tumor(s) dictates how the resection will be performed. For removal of a living donor liver graft, the surgeons need to consider preservation of vessels in the graft as well as minimizing the ischemic injury to the graft during surgery. In a recent report from one center, no lifethreatening complications occurred following 100 donor hepatectomies (17). In the case of hepatectomy as a pretreatment for hepatocyte transplantation the only concern for the surgeon will be safety of the patient. The surgeon will choose the tissue to be resected and will perform the procedure in the safest and easiest way. Hepatectomy prior to hepatocyte transplantation has already been done in a series of patients transplanted for familial hypercholesterolemia in 1992-1994. These patients underwent left lateral segment sectionectomy to 
harvest tissue for hepatocyte isolation and subsequent retroviral transduction of the low density lipoprotein (LDL) receptor (22). Transplantation of transduced autologous hepatocytes was performed on day 3 postoperation. The surgical safety of this procedure was thoroughly studied and was reported without any major complications (50). In this, as with other studies conducted in primates, the proportion of engrafted cells was extremely low $(1: 10,000)$ (3). A $20 \%$ hepatectomy in the nonhuman primate model (macaca) corresponding to left lobe resection was not sufficient to induce liver regeneration and promote cell engraftment. Recently, laparoscopic surgery has been used for liver resection, showing an improvement in the operative results and postoperative course (12). This minimally invasive approach seems suitable if hepatectomy is considered as a pretreatment for hepatocyte transplantation.

What remains to be determined is whether, and at what extent, hepatectomy will generate sufficient signals to improve the engraftment or proliferation of transplanted hepatocytes. The timing of the transplantation after hepatectomy will likely be important. Efimova et al. (14) measured growth factors in serum of healthy individuals after living related liver donation and showed that HGF increased 12-fold already $2 \mathrm{~h}$ postoperation and thereafter stabilized at a threefold higher level compared to preoperation for 5 days. Introducing partial hepatic resection will also be important as it is likely that future treatment regiments may require a combination of procedures. Once hepatocyte transplantation procedures become successful, one could also envision that living donors and domino hepatocyte transplantation will be possible.

\section{SUMMARY}

The purpose of this consensus meeting was to gather together experts from the field to discuss ways to improve the efficacy of current hepatocyte transplantation protocols. Points highlighted at the meeting were that more information from the different centers about the donor selection criteria and the quality control analysis of the cells transplanted would be helpful to compare procedures done at different centers. The participants also concluded that the development of new technologies, particularly those based on stem/progenitor cells, should be studied as methods to overcome the shortage of organs for cell isolation. Clinically acceptable methods to enhance cell engraftment and liver repopulation, such as hepatic irradiation and/or reversible portal embolization or resection, have proven safe in animal models and translation to human application is currently ongoing. If preclinical results can be reproduced in humans, it will be a significant step forward for the field of hepatocyte transplantation.
ACKNOWLEDGMENT: The authors declare no conflicts of interest.

\section{References}

1. Allen, K. J.; Mifsud, N. A.; Williamson, R.; Bertolino, P.; Hardikar, W. Cell-mediated rejection results in allograft loss after liver cell transplantation. Liver Transpl. 14:688694; 2008.

2. Amariglio, N.; Hirshberg, A.; Scheithauer, B. W.; Cohen, Y.; Loewenthal, R.; Trakhtenbrot, L.; Paz, N.; KorenMichowitz, M.; Waldman, D.; Leider-Trejo, L.; Toren, A.; Constantini, S.; Rechavi, G. Donor-derived brain tumor following neural stem cell transplantation in an ataxia telangiectasia patient. PLoS Med. 6:e1000029; 2009.

3. Andreoletti, M.; Loux, N.; Vons, C.; Nguyen, T. H.; Lorand, I.; Mahieu, D.; Simon, L.; Di Rico, V.; Vingert, B.; Chapman, J.; Briand, P.; Schwall, R.; Hamza, J.; Capron, F.; Bargy, F.; Franco, D.; Weber, A. Engraftment of autologous retrovirally transduced hepatocytes after intraportal transplantation into nonhuman primates: Implication for ex vivo gene therapy. Hum. Gene Ther. 12: 169-179; 2001.

4. Azuma, H.; Paulk, N.; Ranade, A.; Dorrell, C.; Al-Dhalimy, M.; Ellis, E.; Strom, S. C.; Kay, M. A.; Finegold, M.; Grompe, M. Robust expansion of human hepatocytes in Fah-/ -/Rag2-/ -/Il2rg-/ - mice. Nat. Biotechnol. 25: 903-910; 2007.

5. Bernardo, M. E.; Zaffaroni, N.; Novara, F.; Cometa, A. M.; Avanzini, M. A.; Moretta, A.; Montagna, D.; Maccario, R.; Villa, R.; Daidone, M. G.; Zuffardi, O.; Locatelli, F. Human bone marrow derived mesenchymal stem cells do not undergo transformation after long-term in vitro culture and do not exhibit telomere maintenance mechanisms. Cancer Res. 67:9142-9149; 2007.

6. Bohnen, N. I.; Charron, M.; Reyes, J.; Rubinstein, W.; Strom, S. C.; Swanson, D.; Towbin, R. Use of indium111-labeled hepatocytes to determine the biodistribution of transplanted hepatocytes through portal vein infusion. Clin. Nucl. Med. 25:447-450; 2000.

7. Bonora-Centelles, A.; Donato, M. T.; Lahoz, A.; Pareja, E.; Mir, J.; Castell, J. V.; Gomez-Lechon, M. J. Functional characterization of hepatocytes for cell transplantation: Customized cell preparation for each receptor. Cell Transplant. 19:21-28; 2010.

8. Campard, D.; Lysy, P. A.; Najimi, M.; Sokal, E. M. Native umbilical cord matrix stem cells express hepatic markers and differentiate into hepatocyte-like cells. Gastroenterology 134:833-848; 2008.

9. Chen, Y.; Zhou, H.; Sarver, A. L.; Zeng, Y.; Roy-Chowdhury, J.; Steer, C. J.; Sahin, M. B. Hepatic differentiation of liver-derived progenitor cells and their characterization by microRNA analysis. Liver Transpl. 16:1086-1097; 2010.

10. Cheng, K.; Benten, D.; Bhargava, K.; Inada, M.; Joseph, B.; Palestro, C.; Gupta, S. Hepatic targeting and biodistribution of human fetal liver stem/progenitor cells and adult hepatocytes in mice. Hepatology 50:1194-1203; 2009.

11. Dagher, I.; Boudechiche, L.; Branger, J.; Coulomb-Lhermine, A.; Parouchev, A.; Sentilhes, L.; Lin, T.; GroyerPicard, M. T.; Vons, C.; Hadchouel, M.; Pariente, D.; Andreoletti, M.; Franco, D.; Weber, A. Efficient hepatocyte engraftment in a nonhuman primate model after partial portal vein embolization. Transplantation 82:1067$1073 ; 2006$. 
12. Dagher, I.; O'Rourke, N.; Geller, D. A.; Cherqui, D. Belli, G.; Gamblin, T. C.; Lainas, P.; Laurent, A.; Nguyen, K. T.; Marvin, M. R.; Thomas, M.; Ravindra, K.; Fielding, G.; Franco, D.; Buell, J. F. Laparoscopic major hepatectomy: An evolution in standard of care. Ann. Surg. 250: 856-860; 2009.

13. Donato, M. T.; Lahoz, A.; Montero, S.; Bonora, A.; Pareja, E.; Mir, J.; Castell, J. V.; Gomez-Lechon, M. J. Functional assessment of the quality of human hepatocyte preparations for cell transplantation. Cell Transplant. 17: 1211-1219; 2008.

14. Efimova, E. A.; Glanemann, M.; Nussler, A. K.; Schumacher, G.; Settmacher, U.; Jonas, S.; Nussler, N.; Neuhaus, P. Changes in serum levels of growth factors in healthy individuals after living related liver donation. Transplant. Proc. 37:1074-1075; 2005.

15. Enami, Y.; Bandi, S.; Kapoor, S.; Krohn, N.; Joseph, B.; Gupta, S. Hepatic stellate cells promote hepatocyte engraftment in rat liver after prostaglandin-endoperoxide synthase inhibition. Gastroenterology 136:2356-2364; 2009.

16. Fausto, N. Liver regeneration. J. Hepatol. 32:19-31; 2000.

17. Fernandes, R.; Pacheco-Moreira, L. F.; Enne, M.; Steinbruck, K.; Alves, J. A.; Filho, G. D.; Gouvea, G.; Martinho, J. M. Surgical complications in 100 donor hepatectomies for living donor liver transplantation in a single Brazilian center. Transplant. Proc. 42:421-423; 2010.

18. Fisher, R. A.; Strom, S. C. Human hepatocyte transplantation: Worldwide results. Transplantation 82:441-449; 2006.

19. Gangappa, S.; Larsen, C. P. Immunosuppressive protocols for pig-to-human islet transplantation: Lessons from preclinical non-human primate models. Xenotransplantation $15: 107-111 ; 2008$.

20. Good, A. H.; Cooper, D. K.; Malcolm, A. J.; Ippolito, R. M.; Koren, E.; Neethling, F. A.; Ye, Y.; Zuhdi, N.; Lamontagne, L. R. Identification of carbohydrate structures that bind human antiporcine antibodies: Implications for discordant xenografting in humans. Transplant. Proc. 24:559-562; 1992.

21. Gramignoli, R.; Marongiu, F.; Sharma, S.; Dorko, K.; Tahan, V.; Geller, D. A.; Venkataramanan, R.; Ellis, E. C. S.; Strom, S. C. A new collagenase/protease preparation for isolation of hepatocytes for clinical transplantation. Hepatology 50:729; 2009.

22. Grossman, M.; Rader, D. J.; Muller, D. W.; Kolansky, D. M.; Kozarsky, K.; Clark, 3rd, B. J.; Stein, E. A.; Lupien, P. J.; Brewer, Jr., H. B.; Raper, S. E.; Wilson, J. M. A pilot study of ex vivo gene therapy for homozygous familial hypercholesterolaemia. Nat. Med. 1:11481154; 1995

23. Gupta, S.; Rajvanshi, P.; Sokhi, R.; Slehria, S.; Yam, A.; Kerr, A.; Novikoff, P. M. Entry and integration of transplanted hepatocytes in rat liver plates occur by disruption of hepatic sinusoidal endothelium. Hepatology 29:509519; 1999.

24. Han, B.; Lu, Y.; Meng, B.; Qu, B. Cellular loss after allogenic hepatocyte transplantation. Transplantation 87:1-5; 2009.

25. Haridass, D.; Yuan, Q.; Becker, P. D.; Cantz, T.; Iken, M.; Rothe, M.; Narain, N.; Bock, M.; Norder, M.; Legrand, N.; Wedemeyer, H.; Weijer, K.; Spits, H.; Manns, M. P.; Cai, J.; Deng, H.; Di Santo, J. P.; Guzman, C. A.; Ott, M. Repopulation efficiencies of adult hepatocytes, fetal liver progenitor cells, and embryonic stem cell-derived hepatic cells in albumin-promoterenhancer urokinase-type plasminogen activator mice. Am. J. Pathol. 175:1483-1492; 2009.

26. Hering, B. J.; Walawalkar, N. Pig-to-nonhuman primate islet xenotransplantation. Transpl. Immunol. 21:81-86; 2009.

27. Hering, B. J.; Wijkstrom, M.; Graham, M. L.; Hardstedt, M.; Aasheim, T. C.; Jie, T.; Ansite, J. D.; Nakano, M.; Cheng, J.; Li, W.; Moran, K.; Christians, U.; Finnegan, C.; Mills, C. D.; Sutherland, D. E.; Bansal-Pakala, P.; Murtaugh, M. P.; Kirchhof, N.; Schuurman, H. J. Prolonged diabetes reversal after intraportal xenotransplantation of wild-type porcine islets in immunosuppressed nonhuman primates. Nat. Med. 12:301-303; 2006.

28. Joseph, B.; Kumaran, V.; Berishvili, E.; Bhargava, K. K.; Palestro, C. J.; Gupta, S. Monocrotaline promotes transplanted cell engraftment and advances liver repopulation in rats via liver conditioning. Hepatology 44:1411-1420; 2006.

29. Joseph, B.; Malhi, H.; Bhargava, K. K.; Palestro, C. J.; McCuskey, R. S.; Gupta, S. Kupffer cells participate in early clearance of syngeneic hepatocytes transplanted in the rat liver. Gastroenterology 123:1677-1685; 2002.

30. Khuu, D. N.; Scheers, I.; Ehnert, S.; Jazouli, N.; Nyabi, O.; Buc-Calderon, P.; Meulemans, A.; Nussler, A.; Sokal, E.; Najimi, M. In vitro differentiated adult human liver progenitor cells display mature hepatic metabolic functions: A potential tool for in vitro pharmacotoxicological testing. Cell Transplant. 20(2):287-302; 2011.

31. Kim, K. S.; Joseph, B.; Inada, M.; Gupta, S. Regulation of hepatocyte engraftment and proliferation after cytotoxic drug-induced perturbation of the rat liver. Transplantation 80:653-659; 2005.

32. Koenig, S.; Krause, P.; Schmidt, T. K.; Rave-Fraenk, M.; Rothe, H.; Hermann, R. M.; Becker, H.; Hess, C. F.; Christiansen, H. Irradiation as preparative regimen for hepatocyte transplantation causes prolonged cell cycle block. Int. J. Radiat. Biol. 84:285-298; 2008.

33. Koenig, S.; Stoesser, C.; Krause, P.; Becker, H.; Markus, P. M. Liver repopulation after hepatocellular transplantation: Integration and interaction of transplanted hepatocytes in the host. Cell Transplant. 14:31-40; 2005.

34. Koenig, S.; Yuan, Q.; Krause, P.; Christiansen, H.; RaveFraenk, M.; Kafert-Kasting, S.; Kriegbaum, H.; Schneider, A.; Ott, M.; Meyburg, J. Regional transient portal ischemia and irradiation as preparative regimen for hepatocyte transplantation. Cell Transplant. 20(2):303-311; 2011

35. Krohn, N.; Kapoor, S.; Enami, Y.; Follenzi, A.; Bandi, S.; Joseph, B.; Gupta, S. Hepatocyte transplantation-induced liver inflammation is driven by cytokines-chemokines associated with neutrophils and Kupffer cells. Gastroenterology 136:1806-1817; 2009.

36. Kuwaki, K.; Tseng, Y. L.; Dor, F. J.; Shimizu, A.; Houser, S. L.; Sanderson, T. M.; Lancos, C. J.; Prabharasuth, D. D.; Cheng, J.; Moran, K.; Hisashi, Y.; Mueller, N.; Yamada, K.; Greenstein, J. L.; Hawley, R. J.; Patience, C.; Awwad, M.; Fishman, J. A.; Robson, S. C.; Schuurman, H. J.; Sachs, D. H.; Cooper, D. K. Heart transplantation in baboons using alpha1,3-galactosyltransferase geneknockout pigs as donors: Initial experience. Nat. Med. 11: 29-31; 2005

37. Laconi, E.; Oren, R.; Mukhopadhyay, D. K.; Hurston, E.; Laconi, S.; Pani, P.; Dabeva, M. D.; Shafritz, D. A. 
Long-term, near-total liver replacement by transplantation of isolated hepatocytes in rats treated with retrorsine. Am. J. Pathol. 153:319-329; 1998.

38. Lainas, P.; Boudechiche, L.; Osorio, A.; Coulomb, A.; Weber, A.; Pariente, D.; Franco, D.; Dagher, I. Liver regeneration and recanalization time course following reversible portal vein embolization. J. Hepatol. 49:354362; 2008.

39. Mahieu-Caputo, D.; Allain, J. E.; Branger, J.; Coulomb, A.; Delgado, J. P.; Andreoletti, M.; Mainot, S.; Frydman, R.; Leboulch, P.; Di Santo, J. P.; Capron, F.; Weber, A. Repopulation of athymic mouse liver by cryopreserved early human fetal hepatoblasts. Hum. Gene Ther. 15: 1219-1228; 2004.

40. Malhi, H.; Annamaneni, P.; Slehria, S.; Joseph, B.; Bhargava, K. K.; Palestro, C. J.; Novikoff, P. M.; Gupta, S. Cyclophosphamide disrupts hepatic sinusoidal endothelium and improves transplanted cell engraftment in rat liver. Hepatology 36:112-121; 2002.

41. Mei, J.; Sgroi, A.; Mai, G.; Baertschiger, R.; GonelleGispert, C.; Serre-Beinier, V.; Morel, P.; Buhler, L. H. Improved survival of fulminant liver failure by transplantation of microencapsulated cryopreserved porcine hepatocytes in mice. Cell Transplant. 18:101-110; 2009.

42. Nagata, H.; Ito, M.; Cai, J.; Edge, A. S.; Platt, J. L.; Fox, I. J. Treatment of cirrhosis and liver failure in rats by hepatocyte xenotransplantation. Gastroenterology 124: 422-431; 2003.

43. Nagata, H.; Nishitai, R.; Shirota, C.; Zhang, J. L.; Koch, C. A.; Cai, J.; Awwad, M.; Schuurman, H. J.; Christians, U.; Abe, M.; Baranowska-Kortylewicz, J.; Platt, J. L.; Fox, I. J. Prolonged survival of porcine hepatocytes in cynomolgus monkeys. Gastroenterology 132:321-329; 2007.

44. Najimi, M.; Khuu, D. N.; Lysy, P. A.; Jazouli, N.; Abarca, J.; Sempoux, C.; Sokal, E. M. Adult-derived human liver mesenchymal-like cells as a potential progenitor reservoir of hepatocytes? Cell Transplant 16:717-728; 2007.

45. Newman, R. E.; Yoo, D.; LeRoux, M. A.; DanilkovitchMiagkova, A. Treatment of inflammatory diseases with mesenchymal stem cells. Inflamm. Allergy Drug Targets $8: 110-123 ; 2009$.

46. Ohashi, K.; Waugh, J. M.; Dake, M. D.; Yokoyama, T.; Kuge, H.; Nakajima, Y.; Yamanouchi, M.; Naka, H.; Yoshioka, A.; Kay, M. A. Liver tissue engineering at extrahepatic sites in mice as a potential new therapy for genetic liver diseases. Hepatology 41:132-140; 2005.

47. Ohashi, K.; Yokoyama, T.; Yamato, M.; Kuge, H.; Kanehiro, H.; Tsutsumi, M.; Amanuma, T.; Iwata, H.; Yang, J.; Okano, T.; Nakajima, Y. Engineering functional two- and three-dimensional liver systems in vivo using hepatic tissue sheets. Nat. Med. 13:880-885; 2007.

48. Phelps, C. J.; Koike, C.; Vaught, T. D.; Boone, J.; Wells, K. D.; Chen, S. H.; Ball, S.; Specht, S. M.; Polejaeva, I. A.; Monahan, J. A.; Jobst, P. M.; Sharma, S. B.; Lamborn, A. E.; Garst, A. S.; Moore, M.; Demetris, A. J.; Rudert, W. A.; Bottino, R.; Bertera, S.; Trucco, M.; Starzl, T. E.; Dai, Y.; Ayares, D. L. Production of alpha 1,3-galactosyltransferase-deficient pigs. Science 299:411-414; 2003.

49. Puppi, J.; Dhawan, A. Human hepatocyte transplantation overview. Methods Mol. Biol. 481:1-16; 2009.

50. Raper, S. E.; Grossman, M.; Rader, D. J.; Thoene, J. G.; Clark, 3rd, B. J.; Kolansky, D. M.; Muller, D. W.; Wilson, J. M. Safety and feasibility of liver-directed ex vivo gene therapy for homozygous familial hypercholesterolemia. Ann. Surg. 223:116-126; 1996.
51. Rood, P. P.; Bottino, R.; Balamurugan, A. N.; Smetanka, C.; Ayares, D.; Groth, C. G.; Murase, N.; Cooper, D. K.; Trucco, M. Reduction of early graft loss after intraportal porcine islet transplantation in monkeys. Transplantation 83:202-210; 2007.

52. Schmelzer, E.; Wauthier, E.; Reid, L. M. The phenotypes of pluripotent human hepatic progenitors. Stem Cells 24: 1852-1858; 2006.

53. Sempoux, C.; Horsmans, Y.; Geubel, A.; Fraikin, J.; Van Beers, B. E.; Gigot, J. F.; Lerut, J.; Rahier, J. Severe radiation-induced liver disease following localized radiation therapy for biliopancreatic carcinoma: Activation of hepatic stellate cells as an early event. Hepatology 26: 128-134; 1997.

54. Slehria, S.; Rajvanshi, P.; Ito, Y.; Sokhi, R. P.; Bhargava, K. K.; Palestro, C. J.; McCuskey, R. S.; Gupta, S. Hepatic sinusoidal vasodilators improve transplanted cell engraftment and ameliorate microcirculatory perturbations in the liver. Hepatology 35:1320-1328; 2002.

55. Smets, F.; Najimi, M.; Sokal, E. M. Cell transplantation in the treatment of liver diseases. Pediatr. Transplant. 12: $6-13 ; 2008$.

56. Stephenne, X.; Najimi, M.; Ngoc, D. K.; Smets, F.; Hue, L.; Guigas, B.; Sokal, E. M. Cryopreservation of human hepatocytes alters the mitochondrial respiratory chain complex 1. Cell Transplant. 16:409-419; 2007.

57. Stephenne, X.; Vosters, O.; Najimi, M.; Beuneu, C.; Dung, K. N.; Wijns, W.; Goldman, M.; Sokal, E. M. Tissue factor-dependent procoagulant activity of isolated human hepatocytes: Relevance to liver cell transplantation. Liver Transpl. 13:599-606; 2007.

58. Tatsumi, K.; Ohashi, K.; Shima, M.; Nakajima, Y.; Okano, T.; Yoshioka, A. Therapeutic effects of hepatocyte transplantation on hemophilia B. Transplantation 86:167$170 ; 2008$

59. Terry, C.; Dhawan, A.; Mitry, R. R.; Hughes, R. D. Cryopreservation of isolated human hepatocytes for transplantation: State of the art. Cryobiology 53:149-159; 2006.

60. Uyama, S.; Kaufmann, P. M.; Kneser, U.; Fiegel, H. C.; Pollok, J. M.; Kluth, D.; Vacanti, J. P.; Rogiers, X. Hepatocyte transplantation using biodegradable matrices in ascorbic acid-deficient rats: Comparison with heterotopically transplanted liver grafts. Transplantation 71:1226$1231 ; 2001$.

61. van der Meulen, J. H.; Lewsey, J. D.; Dawwas, M. F.; Copley, L. P. Adult orthotopic liver transplantation in the United Kingdom and Ireland between 1994 and 2005. Transplantation 84:572-579; 2007.

62. van Poll, D.; Parekkadan, B.; Cho, C. H.; Berthiaume, F.; Nahmias, Y.; Tilles, A. W.; Yarmush, M. L. Mesenchymal stem cell-derived molecules directly modulate hepatocellular death and regeneration in vitro and in vivo. Hepatology 47:1634-1643; 2008.

63. Yamanouchi, K.; Zhou, H.; Roy-Chowdhury, N.; Macaluso, F.; Liu, L.; Yamamoto, T.; Yannam, G. R.; Enke, C.; Solberg, T. D.; Adelson, A. B.; Platt, J. L.; Fox, I. J.; RoyChowdhury, J.; Guha, C. Hepatic irradiation augments engraftment of donor cells following hepatocyte transplantation. Hepatology 49:258-267; 2009.

64. Yan, Y.; Xu, W.; Qian, H.; Si, Y.; Zhu, W.; Cao, H.; Zhou, H.; Mao, F. Mesenchymal stem cells from human umbilical cords ameliorate mouse hepatic injury in vivo. Liver Int. 29:356-365; 2009. 